\section{Probing DNA Structure with Hydroxyl Radicals}

This unit describes how to use the hydroxyl radical $(\cdot \mathrm{OH})$ to gain information on the structure of a DNA molecule. Radiolabeled DNA is allowed to react with the hydroxyl radical, which causes strand breaks in the DNA. The broken DNA strands are separated by length via electrophoresis of the reaction products on a denaturing polyacrylamide gel. The cleavage pattern of the DNA is visualized by exposure of the gel to a phosphor imager plate. Quantitative analysis of the cleavage pattern results in an "image" of the shape of the surface of the DNA molecule. Expertise in the techniques of basic molecular biology is necessary to perform this procedure.

CAUTION: This procedure should be performed only by personnel trained in the proper use of the ${ }^{32} \mathrm{P}$ isotope, in Nuclear Regulatory Commission (NRC)-licensed sites. Standard precautions to prevent excessive exposure and radioactive contamination of personnel and equipment must be followed at all times.

\section{PREPARATION OF THE HYDROXYL RADICAL CLEAVAGE PATTERN OF A DNA MOLECULE}

This protocol describes how to perform hydroxyl radical cleavage of a DNA molecule and how to visualize the cleavage pattern by subjecting the reaction products to denaturing gel electrophoresis. A convenient source of the hydroxyl radical is the Fenton reaction of iron(II) EDTA with hydrogen peroxide (Fig. 6.7.1; Udenfriend et al., 1954). Sodium ascorbate is also present in the reaction, to reduce the iron(III) EDTA product of the Fenton reaction back to iron(II) EDTA. Thus, a catalytic cycle is established, which allows the use of very low concentrations of the iron reagent.

\section{Materials}

$1 \mathrm{ng} / \mu \mathrm{L}$ radiolabeled DNA (5'-end-labeled with ${ }^{32} \mathrm{P}$ on one strand; $3000 \mathrm{Ci} / \mathrm{mmol}$; see, e.g., CPMB UNIT 3.5) dissolved in TE buffer, $\mathrm{pH} 8.0$ (APPENDIX 2A)

$1 \times \mathrm{Fe}(\mathrm{II}) \mathrm{EDTA}$ (see recipe)

$10 \mathrm{mM}$ sodium ascorbate

$0.3 \%$ (v/v) hydrogen peroxide $\left(\mathrm{H}_{2} \mathrm{O}_{2}\right)$

$100 \mathrm{mM}$ thiourea

$3 \mathrm{M}$ sodium acetate (APPENDIX 2A)

$85 \%$ and $100 \%(\mathrm{v} / \mathrm{v})$ ethanol

Dry ice/acetone bath

Formamide-containing dye mixture (e.g., loading buffer, UNIT 10.4)

Denaturing poylacrylamide electrophoresis gel $(\sim 30 \times 40 \times 0.04 \mathrm{~cm}$; APPENDIX 3B)

1.5-mL microcentrifuge tubes, siliconized

$25^{\circ}$ and $90^{\circ} \mathrm{C}$ heating blocks

SpeedVac evaporator

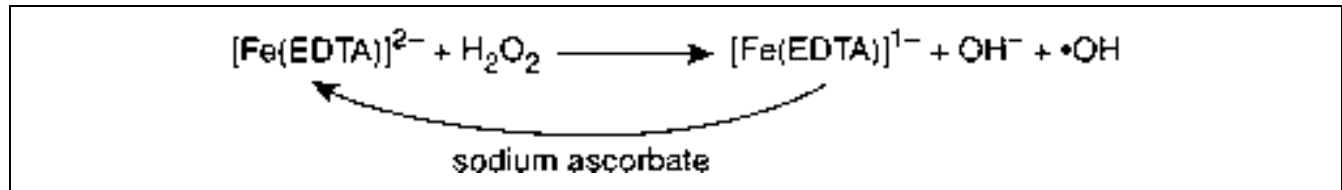

Figure 6.7.1 The Fenton reaction of iron(II) EDTA with hydrogen peroxide to generate the hydroxyl radical.

Contributed by Thomas D. Tullius

Current Protocols in Nucleic Acid Chemistry (2001) 6.7.1-6.7.8

Copyright $\odot 2001$ by John Wiley \& Sons, Inc.
UNIT 6.7

BASIC PROTOCOL

Chemical and Enzymatic Probes for Nucleic Acid Structure

\subsection{1}

Supplement 7 
Phosphor imager with storage phosphor plate that corresponds to the size of the gel Phosphor imaging plate scanner

Additional reagents and equipment for denaturing polyacrylamide gel electrophoresis (PAGE; APPENDIX 3B), drying of high-percentage acryamide denaturing gels (see Support Protocol 1), and image analysis (optional; see Support Protocol 2)

\section{Perform hydroxyl radical cleavage reaction}

1. Add $7 \mu \mathrm{L}$ of $1 \mathrm{ng} / \mu \mathrm{L}$ radiolabeled DNA in $10 \mathrm{mM}$ TE buffer, $\mathrm{pH} 8.0$, to a $1.5-\mathrm{mL}$ siliconized microcentrifuge tube.

2. Place separate drops of the following solutions on the wall of the microcentrifuge tube, above the DNA solution:

$1 \mu \mathrm{L} 1 \times \mathrm{Fe}(\mathrm{II}) \mathrm{EDTA}$

$1 \mu \mathrm{L} 10 \mathrm{mM}$ sodium ascorbate

$1 \mu \mathrm{L} 0.3 \% \mathrm{H}_{2} \mathrm{O}_{2}$.

These solutions make up the cleavage reagent.

3. Close the tube, tap the tube to mix the three drops with the DNA solution, and briefly vortex the solution.

4. Incubate the reaction mixture for $2 \mathrm{~min}$ in a heating block at $25^{\circ} \mathrm{C}$.

The reaction time may need to be adjusted to prevent overdigestion of the sample (see Critical Parameters). If overdigestion is suspected, the intensity of the full-length band in the sample can be compared to a control (step 6) and the reaction time or concentration of cleavage reagents can be reduced as appropriate.

\section{Stop reaction and isolate cleaved DNA}

5. Add $7 \mu \mathrm{L}$ of $100 \mathrm{mM}$ thiourea to the mixture to stop the reaction. Briefly vortex the mixture.

6. Combine $7 \mu \mathrm{L}$ unreacted radiolabeled DNA with $10 \mu \mathrm{L}$ TE buffer in a second tube as a control.

A control is used to ensure that the starting DNA is intact (i.e., that there is no prior cleavage) and to evaluate the extent of cleavage in the sample (see Critical Parameters).

7. Add $3 \mu \mathrm{L}$ of $3 \mathrm{M}$ sodium acetate and $100 \mu \mathrm{L}$ of $100 \%$ ethanol to the sample and the control, and place in a dry ice/acetone bath for $1 \mathrm{hr}$.

8. Microcentrifuge $30 \mathrm{~min}$ at maximum speed, $4^{\circ} \mathrm{C}$, to pellet the DNA.

9. Rinse the DNA pellet twice with $85 \%$ ethanol, centrifuging for 5 min after each rinse.

10. Dry the DNA pellet in a SpeedVac evaporator under vacuum.

If the DNA molecule under study is a short oligonucleotide (fewer than 20 base pairs), ethanol precipitation often is inefficient at pelleting the DNA. Therefore, for short oligonucleotides, steps 7 to 10 are skipped and the DNA is isolated directly by lyophilization of the sample in a SpeedVac evaporator. The disadvantage of this procedure is that any salts present in the reaction mixture are dried down along with the DNA, and problems with denaturing gel electrophoresis may occur. Such problems include poorly shaped gel bands and marked narrowing of the lane near the bottom of the gel. If these problems occur, steps should be taken to minimize the size of the sample and the concentration of salts in the sample.

Probing DNA

Structure with

Hydroxyl

Radicals 
11. Dissolve the DNA pellet in $4 \mu \mathrm{L}$ formamide-containing dye mixture.

12. To denature the DNA, heat the DNA sample at $90^{\circ} \mathrm{C}$ for $3 \mathrm{~min}$, and then quickly cool it by plunging it into ice.

13. Load the DNA sample onto a denaturing polyacrylamide gel that has been prepared in an apparatus suitable for sequencing DNA (see APPENDIX $3 B$ for details on denaturing PAGE).

To study short DNA molecules ( 20 base pairs), use a high-percentage gel (20\% or $25 \%$ acrylamide). Longer DNA fragments require a lower-percentage gel (e.g., 8\% or 10\%).

CAUTION: Acrylamide is a neurotoxin; always wear gloves, safety glasses, and a surgical mask when working with acrylamide powder.

14. Electrophorese the sample for a time appropriate to separate the cleavage products of interest (usually $\sim 2 \mathrm{hr}$ ).

The time of electrophoresis depends on the percentage of poylacrylamide in the gel, the size of the DNA fragments to be separated, and the current (i.e., at constant voltage, the wattage) at which the gel is run. The current should be set so that the gel runs fairly "hot" $\left(\sim 65^{\circ} \mathrm{C}\right)$ to ensure that the DNA sample remains denatured during electrophoresis. Be aware, though, that too much heat will cause the glass plates to crack!

15. Dry the gel using a gel dryer (see Support Protocol 1).

16. Expose the gel to a phosphor imager plate.

This can take several hours to a few days, depending on the level of radioactivity of the bands on the gel.

17. Scan the phosphor imager plate.

If desired, analysis of the gel can be performed using image analysis software (see Support Protocol 2).

\section{DRYING A HIGH-PERCENTAGE POLYACRYLAMIDE DENATURING GEL}

Drying a low-percentage polyacrylamide gel (8\% to $10 \%$ polyacrylamide) is straightforward (see APPENDIX $3 B$ ). Drying a high-percentage gel (20\% to $25 \%$ polyacrylamide) can be tricky, because such a gel does not stick well to the filter paper that is used to pull the gel off the glass plate before drying. High-percentage gels are used for high-resolution separation of shorter DNA molecules (Balasubramanian et al., 1998), and so are important for use in chemical probe experiments to determine DNA structure.The author's laboratory has developed a procedure that works well for drying high-percentage gels (Shafer et al., 1989). The key to the procedure is to first transfer the gel to plastic wrap, which clings well and provides mechanical support to the gel.

\section{Materials}

Gel (see Basic Protocol)

Plastic wrap: 12- or 18-in. ( 30- or 45-cm) Saran Wrap or Reynolds film

Whatman $3 \mathrm{MM}$ filter paper

Gel dryer

1. After running the gel, carefully lift the larger glass plate off the gel.

2. Cover the gel with plastic wrap. Trim the edges of the plastic wrap so that the wrap extends 2 in. $(5 \mathrm{~cm})$ beyond the edges of the gel plate.

3. Using the plastic wrap to support the gel, turn the gel plate over so that the second glass plate is now on top.

Chemical and Enzymatic Probes for Nucleic Acid Structure

\subsection{3}

Supplement 7 
SUPPORT PROTOCOL 2

4. Carefully pull the gel away from the glass plate, starting at the top of the gel.

The gel should remain on the plastic wrap.

5. Trim two pieces of Whatman 3MM filter paper to fit the gel, and place on the gel.

6. Carefully invert the filter paper/gel/plastic wrap sandwich so that the plastic wrap is on top. Remove air bubbles by brushing the plastic wrap with a piece of filter paper.

7. Dry the gel using a gel dryer.

\section{ANALYSIS OF THE CLEAVAGE PATTERN}

While the image of the gel produced in the Basic Protocol can provide much information, hydroxyl radical cleavage patterns often exhibit subtle features. Small differences in cleavage between one nucleotide and another can be difficult to discern by eye alone. Fortunately, the image of the gel that is obtained by the scanning device can be further analyzed using software programs for image analysis.

This protocol describes the basic steps involved in quantitative analysis of the cleavage pattern using readily available software. The goal of this method is to deconvolute the closely spaced bands in a cleavage pattern, and integrate each band. The author's laboratory has found that the Lorentzian function provides a very good analytical description of the bands that are produced by phosphor imager analysis of a gel (Shadle et al., 1997). Each band in the cleavage pattern is fitted by a Lorentzian function using nonlinear least-squares fitting methods. One parameter of the Lorentzian function is directly proportional to the area of the band. These band areas are plotted as a histogram to provide a quantitative cleavage pattern. One benefit of this method of analysis is that once the bands of a lane are deconvoluted and integrated, it is a simple matter to compare one cleavage pattern to another, for normalization, subtraction, and other purposes.

A similar but more elaborate whole-band analysis method, using the software program GelExplorer, is described in Shadle et al. (1997). See Internet Resources for the URL of the GelExplorer manual.

\section{Materials}

Computerized image of gel obtained by scanning the storage phosphor plate (see Basic Protocol)

Personal computer running software for image analysis:

ImageQuant (Molecular Dynamics)

Origin, with Peak Fitting Module (OriginLab)

Microsoft Excel (optional)

1. Perform a linescan of the gel lane of interest, using ImageQuant.

2. Transfer the linescan to Origin.

3. Using the Peak Fitting Module of Origin, simultaneously fit a Lorentzian function to each peak in the cleavage pattern.

4. Plot the integrals of the bands, using Origin or Microsoft Excel.

Probing DNA Structure with Hydroxyl Radicals 
Use ultrapure (e.g., Milli-Q) water in all recipes and protocol steps. For common stock solutions, see APPENDIX 2A; for suppliers, see SUPPLIERS APPENDIX.

\section{$\mathrm{Fe}(\mathrm{II}) \mathrm{EDTA}, 1 \times$}

$5 \times$ stock solution: Dissolve $0.098 \mathrm{~g}$ of ferrous ammonium sulfate hexahydrate $\left[\left(\mathrm{NH}_{4}\right)_{2} \mathrm{Fe}\left(\mathrm{SO}_{4}\right)_{2} \cdot 6 \mathrm{H}_{2} \mathrm{O}\right]$ and $0.186 \mathrm{~g}$ of $\mathrm{Na}_{2} \mathrm{EDTA} \cdot 2 \mathrm{H}_{2} \mathrm{O}$ in $50 \mathrm{~mL}$ of water. Vortex the solution for several minutes to dissolve as much solid as possible. Filter solution through a $0.45-\mu \mathrm{m}$ polypropylene filter - a very light greenish-yellow (or perhaps colorless) solution is obtained (concentration, $5 \mathrm{mM}\left(\mathrm{NH}_{4}\right)_{2} \mathrm{Fe}\left(\mathrm{SO}_{4}\right)_{2} / 10 \mathrm{mM}$ EDTA). Store in $100-\mu \mathrm{L}$ aliquots in microcentrifuge tubes up to several months at $-20^{\circ} \mathrm{C}$.

$1 \times$ working solution: Immediately before use, dilute 1 part $5 \times$ stock solution with 4 parts water (concentration, $1 \mathrm{mM}\left(\mathrm{NH}_{4}\right)_{2} \mathrm{Fe}\left(\mathrm{SO}_{4}\right)_{2} / 2 \mathrm{mM}$ EDTA).

\section{COMMENTARY}

\section{Background Information}

The structure of any particular doublestranded DNA molecule differs from the canonical B-form structure, primarily due to stacking and other interactions between successive base pairs in the DNA double helix. The shape of the surface of a DNA molecule therefore is not perfectly regular, but instead reflects the underlying sequence-dependent structural variability of the DNA. Such structural variations in DNA, whether large or subtle, may contribute to the ability of a protein to recognize a particular DNA sequence, and so are important to characterize. DNA also can adopt structures radically different from the typical double helix, for example the four-stranded Holliday junction that is an intermediate in genetic recombination. Such unusual DNA structures can be difficult to study by standard methods.

The hydroxyl radical has proven to be a highly useful probe of the shape of the surface of DNA. It works by causing strand breaks at each nucleotide in a DNA molecule. The main advantages of the hydroxyl radical as a chemical probe of DNA structure are that it reacts with every nucleotide in a DNA molecule that is exposed to the solvent, that it is a very small molecule, and that fine details of DNA structure can potentially be revealed.

This highly reactive free radical causes a DNA strand to break by abstracting a hydrogen atom from a deoxyribose residue in the backbone of the DNA. The resulting strand breaks are detected by electrophoresis of the reaction products on a denaturing gel. Every nucleotide of a double-stranded DNA molecule is susceptible to attack by the hydroxyl radical. However, the nucleotides in a DNA molecule do not all react to precisely the same extent, because the exposure of each deoxyribose residue to the solvent differs due to sequence-dependent structural variations in the DNA. Quantitation of the cleavage pattern provides an abstract "image" of the shape of the surface of the DNA molecule. Other chemical probes have been developed that recognize specific structural features of DNA, and are described in other units in Chapter 6.

The hydroxyl radical has been used to study a wide variety of unusual DNA structures (Price and Tullius, 1992). Two examples are bent A-tract DNA (Burkhoff and Tullius, 1987, 1988; Price and Tullius, 1993) and the fourstranded Holliday junction recombination intermediate (Churchill et al., 1988; Kimball et al., 1990).

\section{Critical Parameters}

Several parameters are critical for the success of the Basic Protocol. The DNA must be intact before the hydroxyl radical cleavage reaction is conducted. Because the hydroxyl radical cleaves DNA at every accessible nucleotide, any preexisting (background) cuts in the DNA strand interfere with analysis of the hydroxyl radical-induced cuts. To check the integrity of the starting DNA, include in the experiment a control sample of DNA that is not subjected to hydroxyl radical cleavage, and run this sample on the gel adjacent to the experimental samples. The control untreated sample should show no bands other than the band corresponding to the intact full-length DNA molecule. If cleavage is seen in this lane, the DNA should be further purified, or the DNA molecule should be prepared again.

The reagents used to initiate hydroxyl radical cleavage must be active. Iron(II) EDTA is
Chemical and Enzymatic Probes for Nucleic Acid Structure 
not indefinitely stable, because iron(II) is subject to oxidation to iron(III) and the eventual formation of a precipitate. Iron(II) EDTA stock solutions should be stored frozen, and thawed for use immediately before the experiment.

Sodium ascorbate also is subject to oxidation, both in the solid state and in solution. Oxidized ascorbate will not reduce the iron(III) product of the reaction back to iron(II), and so the cleavage reagent is not active. A fresh bottle of sodium ascorbate is used to prepare a stock solution, which is divided into aliquots in microcentrifuge tubes and kept frozen until needed for an experiment.

The DNA must not be overdigested by the hydroxyl radical. The goal is to have one or fewer cleavages in any individual DNA strand. This can be achieved operationally by limiting the reaction so that $<30 \%$ of the DNA molecules in the sample are cleaved. Thus, $70 \%$ of the DNA in the sample will run as intact, fulllength DNA in the gel. If overdigestion is suspected, compare the intensity of the full-length band in a control, untreated DNA sample with the intensity of the full-length band in a sample treated with hydroxyl radical. This can be accomplished by a short exposure of the gel to the phosphor imager plate. The intensity of the treated sample's full-length band should be no less than $70 \%$ of the control band's intensity. If the sample is overdigested, adjust the time of reaction or the concentration of the iron(II) EDTA in the reaction mixture.

This unit describes the use of 5 '-radiolabeled DNA in a hydroxyl radical cleavage experiment. DNA singly end-labeled at the $3^{\prime}$ end could in principle also be used in this protocol. However, very high-resolution gel electrophoresis shows that a major product of DNA cleavage by the hydroxyl radical is a DNA strand terminated by a $5^{\prime}$ aldehyde group (Fig. 6.7.2; Balasubramanian et al., 1998). A DNA strand with this type of terminus has an anomalous gel mobility, making detailed quantitation of the gel pattern difficult. Therefore $5^{\prime}$-radiolabeled DNA is best for studies of DNA structure using the hydroxyl radical.

\section{Troubleshooting}

Common problems that may arise in the course of probing DNA structure with hydroxyl radicals, along with their possible causes and solutions, are listed in Table 6.7.1.

\section{Anticipated Results}

The results of this protocol will be a ladder of bands on a denaturing polyacrylamide gel for a sample treated with the hydroxyl radical, and a single intense full-length band for the control untreated sample. The bands in the

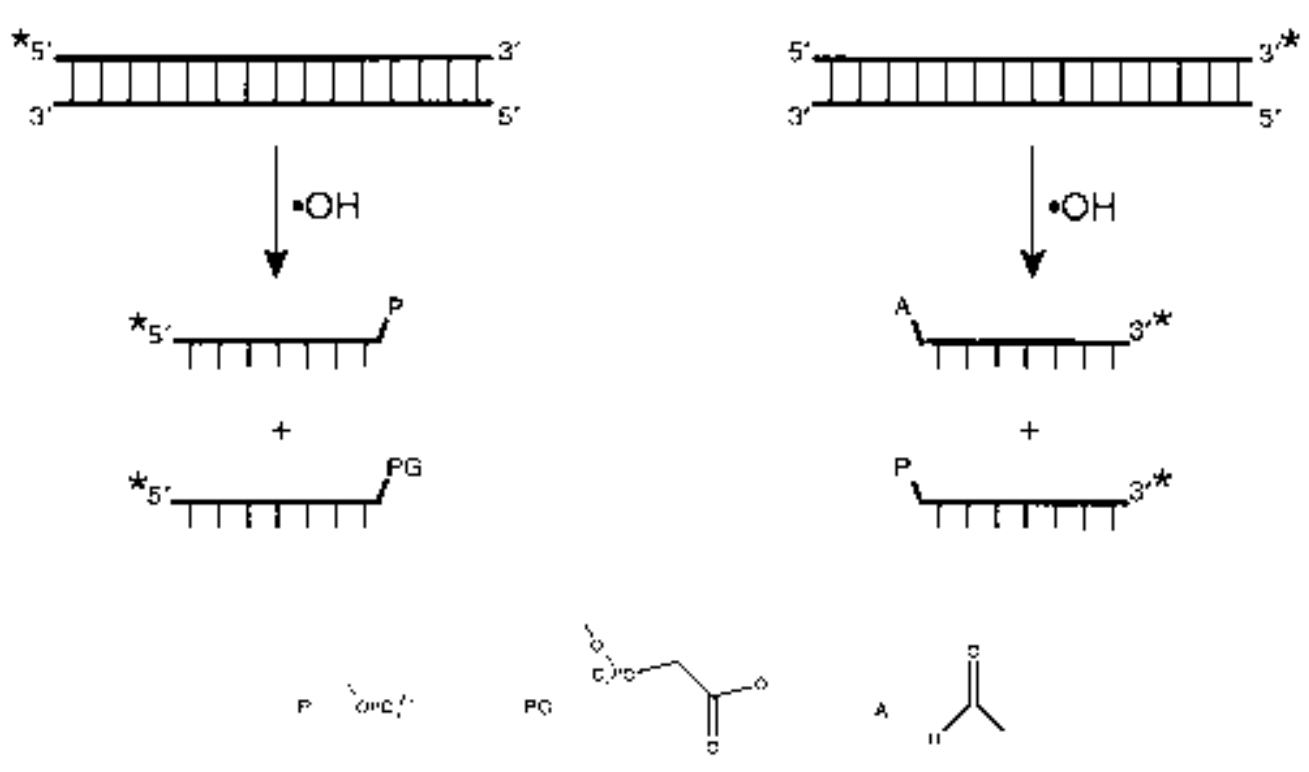

Probing DNA Structure with Hydroxyl Radicals

Figure 6.7.2 Hydroxyl radical cleavage using 5'- and 3'-end-labeled DNA. The major product for each is a DNA strand terminated by phosphate at the site of strand breakage. With $3^{\prime}$-labeled DNA, the aldehyde-terminated strand also is produced in substantial amounts, leading to difficulties in quantitation. 
Table 6.7.1 Troubleshooting Guide for Probing DNA Structure with Hydroxyl Radicals

\begin{tabular}{|c|c|c|}
\hline Problem & Possible cause & Solution \\
\hline \multirow[t]{2}{*}{$\begin{array}{l}\text { No cleavage pattern is } \\
\text { observed }\end{array}$} & $\begin{array}{l}\text { Ascorbate reducing agent is } \\
\text { inactive due to oxidation (see } \\
\text { Critical Parameters) }\end{array}$ & $\begin{array}{l}\text { Prepare a fresh ascorbate } \\
\text { solution }\end{array}$ \\
\hline & $\begin{array}{l}\text { DNA sample contains radical } \\
\text { scavengers (glycerol is } \\
\text { commonly used to stabilize } \\
\text { proteins, and sometimes is } \\
\text { used in other buffers, and is an } \\
\text { excellent radical scavenger) }\end{array}$ & $\begin{array}{l}\text { Remove radical scavengers } \\
\text { from the buffer }\end{array}$ \\
\hline $\begin{array}{l}\text { Bands are poorly shaped, } \\
\text { and become progressively } \\
\text { more narrow toward the } \\
\text { bottom of the gel }\end{array}$ & $\begin{array}{l}\text { DNA sample contains too } \\
\text { much salt }\end{array}$ & $\begin{array}{l}\text { Perform additional ethanol } \\
\text { precipitations to remove salt, or } \\
\text { use less salt in the reaction } \\
\text { mixture }\end{array}$ \\
\hline $\begin{array}{l}\text { Control (untreated) DNA } \\
\text { shows cleavage }\end{array}$ & DNA sample has deteriorated & $\begin{array}{l}\text { Prepare fresh DNA. Do not } \\
\text { store DNA for an extended } \\
\text { time once it is radiolabeled, } \\
\text { especially at high specific } \\
\text { activity, as autoradiolysis can } \\
\text { damage the DNA molecule. }\end{array}$ \\
\hline
\end{tabular}

treated sample should be fairly uniform in intensity, since the hydroxyl radical cleaves each nucleotide in a B-form double helix to a nearly equal extent.

\section{Time Considerations}

Radiolabeling the DNA, performing the hydroxyl radical cleavage reaction, and isolating the DNA can be accomplished in one working day or less. Preparing and running the denaturing gel to separate the cleavage products takes another day. The time of exposure of the gel to the phosphor plate varies depending on the radioactivity of the sample, but 1 to 3 days is typically sufficient. Quantitative analysis of a gel takes a day.

\section{Literature Cited}

Balasubramanian, B., Pogozelski, W.K., and Tullius, T.D. 1998. DNA strand breaking by the hydroxyl radical is governed by the accessible surface areas of the hydrogen atoms of the DNA backbone. Proc. Natl. Acad. Sci. U.S.A. 95:97389743.

Burkhoff, A.M. and Tullius, T.D. 1987. The unusual conformation adopted by the adenine tracts in kinetoplast DNA. Cell 48:935-943.

Burkhoff, A.M. and Tullius, T.D. 1988. Structural details of an adenine tract that does not cause DNA to bend. Nature 331:455-457.
Churchill, M.E.A., Tullius, T.D., Kallenbach, N.R., and Seeman, N.C. 1988. A Holliday recombination intermediate is twofold symmetric. Proc. Natl. Acad. Sci. U.S.A. 85:4653-4656.

Kimball, A., Guo, Q., Lu, M., Cunningham, R.P., Kallenbach, N.R., Seeman, N.C., and Tullius, T.D. 1990. Construction and analysis of parallel and antiparallel Holliday junctions. J. Biol. Chem. 265:6544-6547.

Price, M.A. and Tullius, T.D. 1992. Using the hydroxyl radical to probe DNA structure. Methods Enzymol. 212:194-219.

Price, M.A. and Tullius, T.D. 1993. How the structure of an adenine tract depends on sequence context. A new model for the structure of $\mathrm{T}_{\mathrm{n}} \mathrm{A}_{\mathrm{n}}$ DNA sequences. Biochemistry 32:127-136.

Shadle, S.E., Allen, D.F., Guo, H., Pogozelski, W.K., Bashkin, J.S., and Tullius, T.D. 1997. Quantitative analysis of electrophoresis data: Novel curve fitting methodology and its application to the determination of a protein-DNA binding constant. Nucl. Acids Res. 25:850-861.

Shafer, G.E., Price, M.A., and Tullius, T.D. 1989. Use of the hydroxyl radical and gel electrophoresis to study DNA structure. Electrophoresis 10:397-404.

Udenfriend, S., Clark, C.T., Axelrod, J., and Brodie, B.B. 1954. Ascorbic acid in aromatic hydroxylation. J. Biol. Chem. 208:731-739.
Chemical and Enzymatic Probes for Nucleic Acid Structure

6.7.7

Supplement 7 
Key References

Price and Tullius, 1992. See above.

A comprehensive description of the use of the hydroxyl radical as a probe of DNA structure.

\section{Internet Resources}

http://people.bu.edu/tullius/GelExplorer_Manual.pdf

A detailed online manual that describes the use of the GelExplorer software for quantitative analysis of electrophoresis gel patterns.

Contributed by Thomas D. Tullius

Boston University

Boston, Massachussetts

Probing DNA

Structure with

Hydroxyl

Radicals 